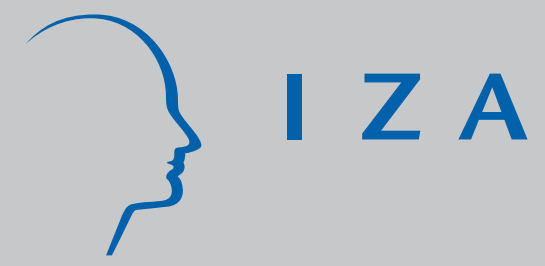

IZA DP No. 9036

Average Wage Gaps and Oaxaca-Blinder Decompositions

Tymon Stoczyński

May 2015

Forschungsinstitut zur Zukunft der Arbeit Institute for the Study of Labor 


\title{
Average Wage Gaps and Oaxaca-Blinder Decompositions
}

\author{
Tymon Słoczyński \\ Warsaw School of Economics \\ and IZA
}
Discussion Paper No. 9036
May 2015

IZA
P.O. Box 7240
53072 Bonn
Germany

\author{
Phone: +49-228-3894-0 \\ Fax: +49-228-3894-180 \\ E-mail: iza@iza.org
}

\begin{abstract}
Any opinions expressed here are those of the author(s) and not those of IZA. Research published in this series may include views on policy, but the institute itself takes no institutional policy positions. The IZA research network is committed to the IZA Guiding Principles of Research Integrity.

The Institute for the Study of Labor (IZA) in Bonn is a local and virtual international research center and a place of communication between science, politics and business. IZA is an independent nonprofit organization supported by Deutsche Post Foundation. The center is associated with the University of Bonn and offers a stimulating research environment through its international network, workshops and conferences, data service, project support, research visits and doctoral program. IZA engages in (i) original and internationally competitive research in all fields of labor economics, (ii) development of policy concepts, and (iii) dissemination of research results and concepts to the interested public.
\end{abstract}

IZA Discussion Papers often represent preliminary work and are circulated to encourage discussion. Citation of such a paper should account for its provisional character. A revised version may be available directly from the author. 


\section{ABSTRACT}

\section{Average Wage Gaps and Oaxaca-Blinder Decompositions}

In this paper I develop a new version of the Oaxaca-Blinder decomposition whose unexplained component recovers a parameter which I refer to as the average wage gap. Under a particular conditional independence assumption, this estimand is equivalent to the average treatment effect (ATE). I also provide treatment-effects reinterpretations of the Reimers, Cotton, and Fortin decompositions as well as estimate average wage gaps, average wage gains for men, and average wage losses for women in the United Kingdom. Conditional wage gaps increase across the wage distribution and therefore, on average, male gains are larger than female losses.

JEL Classification: $\quad \mathrm{C} 21, \mathrm{~J} 31, \mathrm{~J} 71$

Keywords: decomposition methods, gender wage gaps, glass ceilings, treatment effects

Corresponding author:

Tymon Słoczyński

Department of Economics I

Warsaw School of Economics

ul. Madalinskiego 6/8 p. 228

02-513 Warszawa

Poland

E-mail: tymon.sloczynski@gmail.com

\footnotetext{
"A previous version of this paper circulated under the title "Population Average Gender Effects" (IZA DP No. 7315). I am grateful to Krzysztof Karbownik, Michał Myck, and two anonymous referees for detailed comments on earlier drafts of this paper as well as to Arun Advani, Joshua Angrist, Anna Baranowska-Rataj, Thomas Crossley, Steven Haider, Patrick Kline, Mateusz Myśliwski, Ronald Oaxaca, Jörg Schwiebert, Gary Solon, Adam Szulc, Joanna Tyrowicz, Glen Waddell, Rudolf WinterEbmer, Jeffrey Wooldridge, and seminar and conference participants at many institutions for further comments and discussions. I acknowledge financial support from the National Science Centre (grant DEC-2012/05/N/HS4/00395), the Foundation for Polish Science (a START scholarship), and the "Weź stypendium-dla rozwoju" scholarship program. I would also like to thank the Clifford and Mary Corbridge Trust, the Cambridge European Trust, and the Faculty of Economics at the University of Cambridge for financial support which allowed me to undertake graduate studies at the University of Cambridge where this project was started. Data used in this paper come from the UK Data Archive at the University of Essex. It bears no responsibility, however, for data analysis or interpretation presented in this paper.
} 


\section{Introduction}

Since the seminal contributions of Oaxaca (1973) and Blinder (1973), one of the most extensive strands of the literature in empirical labor economics has aimed at decomposing wage gaps into components attributable to group composition and net effects of group membership, often referred to as the explained component and the unexplained component, respectively. Recently, several researchers (Barsky et al., 2002; Black et al., 2006, 2008; Melly, 2006; Fortin et al., 2011; Kline, 2011) have noted that the unexplained component in the most basic version of the Oaxaca-Blinder decomposition can sometimes be interpreted as the average treatment effect on the treated (ATT). ${ }^{1}$ In this paper I extend this literature by deriving a new version of the Oaxaca-Blinder decomposition whose unexplained component can be interpreted as the average treatment effect (ATE), which is likely to be the primary object of interest in various empirical contexts. Because the potential outcome model (see, e.g., Holland, 1986; Imbens and Wooldridge, 2009) is rarely invoked in the wage gap literature, I usually refer to this object as the average wage gap -an equivalent parameter which lacks a causal interpretation.

It is important to note that this new decomposition is distinct from previous versions of the so-called "generalized Oaxaca-Blinder decomposition" (Reimers, 1983; Cotton, 1988; Neumark, 1988; Oaxaca and Ransom, 1994; Fortin, 2008), although it easily fits into this class of models. Different members of this class are defined by the choice of the comparison wage structure-a counterfactual wage setting function with which all actual wages are compared. In this paper I study whether the average wage gap can be recovered with some version of the generalized Oaxaca-Blinder decomposition. I derive such a new model which uses a linear combination of the regression coefficients for both subpopulations (advantaged and disadvantaged workers) as the comparison wage structure. However, these coefficients are weighted in a nonstandard way, namely the population proportion of advantaged workers is used to weight the coefficients for disadvantaged workers, and vice versa. Clearly, such a weighting procedure may at first look counterintuitive. $^{2}$ Nevertheless, within the framework of this paper the role of each group's wage structure is to serve as the counterfactual for the other group, and therefore we should

\footnotetext{
${ }^{1}$ Other contributions to the decomposition literature have recently concentrated on semi- and nonparametric analogues of traditional Oaxaca-Blinder decompositions (Barsky et al., 2002; Black et al., 2006, 2008; Frölich, 2007; Mora, 2008; Nopo, 2008) and extensions to other distributional statistics besides the mean (Juhn et al., 1993; DiNardo et al., 1996; Machado and Mata, 2005; Melly, 2005; Firpo et al., 2007; Chernozhukov et al., 2013).

${ }^{2}$ Note that a similar model had already been used by Duncan and Leigh (1985) in an application to union wage premiums, but such an approach was criticized - as "not a very intuitive procedure" - by Oaxaca and Ransom (1988).
} 
indeed put more weight on the coefficients for the smaller group in order to recover the average wage gap. Note that a similar intuition can also be applied to provide a reinterpretation of the Reimers (1983), Cotton (1988), and Fortin (2008) decompositions. Each of these decompositions is easily shown to recover some generally uninteresting weighted average of conditional wage gaps.

As demonstrated by Fortin et al. (2011), identification of the explained component and the unexplained component requires a set of assumptions: simple counterfactual treatment, overlapping support, and conditional independence/ignorability. The assumptions of a simple counterfactual treatment and conditional independence together imply that the conditional wage distribution remains invariant to manipulations of the marginal distribution of covariates ("invariance of conditional distributions"). Therefore, it is possible to construct a counterfactual wage distribution which would be observed if disadvantaged workers were paid according to the wage setting function of advantaged workers, and vice versa. Then, the unexplained component can be interpreted as a treatment effect provided that the potential outcome model is also invoked-which might not be desirable, however, in the wage gap literature.

In this paper I also provide an empirical example which uses my new decomposition as well as other econometric methods to study gender wage gaps with the UK Labour Force Survey (LFS) data, for each year from 2002 to 2010. In particular, the standard parametric approach is complemented by normalized reweighting and a combination of stratification and different versions of the Oaxaca-Blinder decomposition. Importantly, I provide separate estimates of the average wage gap, the average wage gain for men, and the average wage loss for women. This is the first paper to clarify the distinction between these parameters and provide separate estimates for each of them.

\section{Theory}

\subsection{Framework and Notation}

Consider a population which is divided into two mutually exclusive groups, indexed by $d_{i} \in\{0,1\}$ and referred to as the advantaged group $\left(d_{i}=1\right)$ and the disadvantaged group $\left(d_{i}=0\right)$. For each unit $i$, we also observe a $(\log )$ wage, $y_{i}$, and a row vector of covariates, $X_{i}$. In that case, $\mathrm{E}\left[y_{i} \mid X_{i}=x, d_{i}=1\right]$ is the expected (log) wage of an advantaged worker with observed characteristics $X_{i}=x$ and $\mathrm{E}\left[y_{i} \mid X_{i}=x, d_{i}=0\right]$ is the expected $(\log )$ wage of a disadvantaged worker with these characteristics. Moreover, define the conditional wage gap to be $\tau(x)=\mathrm{E}\left[y_{i} \mid X_{i}=x, d_{i}=1\right]-\mathrm{E}\left[y_{i} \mid X_{i}=x, d_{i}=0\right]$, i.e. the 
gap between the expected (log) wages of an advantaged worker and a disadvantaged worker with $X_{i}=x$. Dependent on the question we wish to answer, we may average $\tau\left(X_{i}\right)$ over the whole population, over the subpopulation of advantaged workers or over the subpopulation of disadvantaged workers. Define the average wage gap to be:

$$
\tau_{\text {gap }}=\mathrm{E}\left[\tau\left(X_{i}\right)\right]
$$

Within the framework of a potential outcome model, and under additional assumptions, this parameter is equivalent to the average treatment effect. Moreover, define the average wage gain for advantaged workers and the average wage loss for disadvantaged workers to be:

$$
\tau_{\text {gain }}=\mathrm{E}\left[\tau\left(X_{i}\right) \mid d_{i}=1\right] \quad \text { and } \quad \tau_{\text {loss }}=\mathrm{E}\left[\tau\left(X_{i}\right) \mid d_{i}=0\right],
$$

respectively. Similarly, under certain conditions, these parameters can be regarded as equivalents of the average treatment effect on the treated and the average treatment effect on the controls. It is also the case that:

$$
\tau_{\text {gap }}=\mathrm{P}\left[d_{i}=1\right] \cdot \tau_{\text {gain }}+\mathrm{P}\left[d_{i}=0\right] \cdot \tau_{\text {loss }} .
$$

Thus, a particular weighted average of the average wage gain for advantaged workers and the average wage loss for disadvantaged workers is equal to the average wage gap.

It is important to note that without further assumptions $\tau(x), \tau_{\text {gap }}, \tau_{\text {gain }}$, and $\tau_{\text {loss }}$ cannot be interpreted as causal or counterfactual; they are also identified from the data. As demonstrated by Fortin et al. (2011), a counterfactual interpretation can be justified by a set of three additional assumptions: simple counterfactual treatment, overlapping support, and conditional independence/ignorability. These assumptions are discussed below for completeness.

Assumption 1 (Simple Counterfactual Treatment). The observed wage structure of advantaged (disadvantaged) workers represents a counterfactual wage structure for disadvantaged (advantaged) workers.

This assumption restricts the analysis to counterfactuals which are based on the observed wage structure for the other group. In other words, the observed wage structure of advantaged workers provides a counterfactual for disadvantaged workers, and vice versa. It is important to note that this assumption rules out the presence of general equilibrium effects, and this might be a substantial restriction in some empirical contexts. 
Assumption 2 (Overlapping Support). Define $\epsilon_{i}$ to be the worker's unobserved characteristics. Then, $0<\mathrm{P}\left[d_{i}=1 \mid X_{i}=x, \epsilon_{i}=e\right]<1$.

The overlapping support assumption ensures that no combination of observed and unobserved characteristics can be used to identify group membership. This restriction has recently become controversial in the gender wage gap literature, because "a significant number of males exhibit[s] a set of characteristics that have no female counterparts, and these characteristics are highly rewarded in the labor markets" (Nopo, 2008); clearly, similar problems can also arise in other empirical contexts.

Assumption 3 (Conditional Independence/Ignorability). Let $\left(d_{i}, X_{i}, \epsilon_{i}\right)$ have a joint distribution. Then, $d_{i} \perp \epsilon_{i} \mid X_{i}$, i.e. the worker's unobserved characteristics are independent of group membership, conditional on observed covariates.

This assumption rules out the presence of unobserved characteristics which would be correlated with both group membership and wages, conditional on observed covariates. Such a requirement is potentially problematic in the case of gender wage gaps, because in most studies there are several omitted variables which have been shown to be correlated with both gender and wages. These unobserved covariates include college major (Brown and Corcoran, 1997; Loury, 1997; Machin and Puhani, 2003; Black et al., 2008), propensity to negotiate wages (Leibbrandt and List, 2014), test scores (Blackburn, 2004), gender role attitudes (Fortin, 2005), absenteeism (Ichino and Moretti, 2009), and various personality traits (Mueller and Plug, 2006; Fortin, 2008; Manning and Swaffield, 2008). ${ }^{3}$

It is important to note that each of these three assumptions is potentially controversial, but they are still required to disentangle the explained component and the unexplained component (Fortin et al., 2011). If we maintain these assumptions, it becomes possible to construct a counterfactual wage distribution which would be observed if disadvantaged workers were paid according to the wage structure of advantaged workers, and vice versa. This counterfactual experiment provides a meaningful interpretation of $\tau_{\text {gap }}$, $\tau_{\text {gain }}$, and $\tau_{\text {loss }}$. The average wage gap, $\tau_{\text {gap }}$, is equal to the difference between mean wages in two counterfactual distributions: in the first distribution, all workers are paid according to the wage setting function of advantaged workers; in the second distribution, all workers are paid according to the wage setting function of disadvantaged workers.

\footnotetext{
${ }^{3}$ Of course, some form of endogeneity might also arise if there are unobserved covariates with different correlation patterns. However, as demonstrated by Fortin et al. (2011), identification of the explained and unexplained components is not threatened unless the conditional independence assumption is violated.
} 
Similarly, the average wage gain for advantaged workers, $\tau_{\text {gain }}$, is equal to the average gap between actual wages of advantaged workers and their counterfactual wages which would be observed if these workers were paid according to the wage structure of disadvantaged workers. Analogously, the average wage loss for disadvantaged workers, $\tau_{\text {loss }}$, is equal to the average gap between counterfactual wages of disadvantaged workers which would be observed if these workers were paid according to the wage structure of advantaged workers and their actual wages. Although $\tau_{\text {loss }}$ might be the most intuitive estimand in some contexts, the decomposition literature has often been concerned with both gains and losses (see, e.g., Fortin, 2008), and therefore $\tau_{\text {gap }}$ and $\tau_{\text {gain }}$ are also usually interesting. Especially, the average wage gap-a noncausal equivalent of the average treatment effect-is likely to be the primary object of interest in many empirical studies.

\subsection{Oaxaca-Blinder Decompositions}

Let the model for outcomes be linear and separable in observed and unobserved characteristics, and allow the regression coefficients to be different for both groups of interest:

$$
y_{i}=X_{i} \beta_{1}+v_{1 i} \quad \text { if } \quad d_{i}=1 \quad \text { and } \quad y_{i}=X_{i} \beta_{0}+v_{0 i} \text { if } \quad d_{i}=0 .
$$

Also, $\mathrm{E}\left[v_{1 i} \mid X_{i}, d_{i}\right]=\mathrm{E}\left[v_{0 i} \mid X_{i}, d_{i}\right]=0$. The raw wage gap, $\mathrm{E}\left[y_{i} \mid d_{i}=1\right]-\mathrm{E}\left[y_{i} \mid d_{i}=0\right]$, can then be decomposed as:

$$
\begin{aligned}
\mathrm{E}\left[y_{i} \mid d_{i}=1\right]-\mathrm{E}\left[y_{i} \mid d_{i}=0\right]= & \mathrm{E}\left[X_{i} \mid d_{i}=1\right] \cdot\left(\beta_{1}-\beta_{0}\right) \\
& +\left(\mathrm{E}\left[X_{i} \mid d_{i}=1\right]-\mathrm{E}\left[X_{i} \mid d_{i}=0\right]\right) \cdot \beta_{0},
\end{aligned}
$$

where the first element, $\mathrm{E}\left[X_{i} \mid d_{i}=1\right] \cdot\left(\beta_{1}-\beta_{0}\right)$, reflects intergroup differences in regression coefficients, and is often referred to as the unexplained component, while the second element, $\left(\mathrm{E}\left[X_{i} \mid d_{i}=1\right]-\mathrm{E}\left[X_{i} \mid d_{i}=0\right]\right) \cdot \beta_{0}$, reflects intergroup differences in mean covariate values, and is often referred to as the explained component. Similarly:

$$
\begin{aligned}
\mathrm{E}\left[y_{i} \mid d_{i}=1\right]-\mathrm{E}\left[y_{i} \mid d_{i}=0\right]= & \mathrm{E}\left[X_{i} \mid d_{i}=0\right] \cdot\left(\beta_{1}-\beta_{0}\right) \\
& +\left(\mathrm{E}\left[X_{i} \mid d_{i}=1\right]-\mathrm{E}\left[X_{i} \mid d_{i}=0\right]\right) \cdot \beta_{1} .
\end{aligned}
$$

The difference between Equations 5 and 6 rests upon using alternate comparison coefficients to calculate the explained component as well as measuring the distance between the regression functions, $\beta_{1}-\beta_{0}$, for a different set of covariate values. Moreover, Equations 5 and 6 recover the average wage gain for advantaged workers and the average 
wage loss for disadvantaged workers, respectively:

$$
\tau_{\text {gain }}=\mathrm{E}\left[X_{i} \mid d_{i}=1\right] \cdot\left(\beta_{1}-\beta_{0}\right) \quad \text { and } \quad \tau_{\text {loss }}=\mathrm{E}\left[X_{i} \mid d_{i}=0\right] \cdot\left(\beta_{1}-\beta_{0}\right) .
$$

There has been a long-lasting tendency in the decomposition literature to claim that the choice of the comparison group in this context (choosing between Equations 5 and 6) is necessarily ambiguous. The standard response has been to suggest alternative wage structures to solve this comparison group choice problem. Such an approach is referred to as "generalized Oaxaca-Blinder", and it involves an alternative decomposition:

$$
\begin{aligned}
\mathrm{E}\left[y_{i} \mid d_{i}=1\right]-\mathrm{E}\left[y_{i} \mid d_{i}=0\right]= & \mathrm{E}\left[X_{i} \mid d_{i}=1\right] \cdot\left(\beta_{1}-\beta^{*}\right)+\mathrm{E}\left[X_{i} \mid d_{i}=0\right] \cdot\left(\beta^{*}-\beta_{0}\right) \\
& +\left(\mathrm{E}\left[X_{i} \mid d_{i}=1\right]-\mathrm{E}\left[X_{i} \mid d_{i}=0\right]\right) \cdot \beta^{*}
\end{aligned}
$$

where $\beta^{*}$ is the set of comparison coefficients, typically referred to as the "nondiscriminatory" or "competitive" wage structure. Note that if $\beta^{*}=\beta_{1}=\beta_{0}$, then there is no unexplained component, because $\beta_{1}=\beta_{0}$ implies that all workers are paid according to the same wage structure. Also, some authors provide a simple interpretation of the two elements of the unexplained component in Equation 8. Namely, $\mathrm{E}\left[X_{i} \mid d_{i}=1\right] \cdot\left(\beta_{1}-\beta^{*}\right)$ is sometimes interpreted as "the amount by which ... productivity characteristics [of advantaged workers] are overvalued", in which case $\mathrm{E}\left[X_{i} \mid d_{i}=0\right] \cdot\left(\beta^{*}-\beta_{0}\right)$ is interpreted as "the amount by which ... productivity characteristics [of disadvantaged workers] are undervalued" (Cotton, 1988). These two objects, in general, do not overlap with $\tau_{\text {gain }}$ and $\tau_{\text {loss }}$. However, for some choices of $\beta^{*}$, they are very closely related.

Several influential papers have been devoted to suggesting alternative sets of comparison coefficients for Equation 8, and these coefficients have often been formulated as $\beta^{*}=\lambda \cdot \beta_{1}+(1-\lambda) \cdot \beta_{0}$ where $\lambda \in[0,1]$ is a weighting factor. If $\lambda=0$, then disadvantaged workers are used as reference, $\beta^{*}=\beta_{0}$, and Equation 8 simplifies to Equation 5. Similarly, if $\lambda=1$, then advantaged workers are used as reference, $\beta^{*}=\beta_{1}$, and Equation 8 simplifies to Equation 6. Alternatively, Reimers (1983) suggested $\lambda=\frac{1}{2}$ and Cotton (1988) suggested $\lambda=\mathrm{P}\left[d_{i}=1\right]$, the population proportion of advantaged workers. Moreover, Neumark (1988) developed a simple model of Beckerian discrimination, and showed that identification of the nondiscriminatory wage structure is ensured, for example, if the utility function of the representative producer is homogeneous of degree zero with respect to labor inputs of advantaged and disadvantaged workers. Such a wage structure can be approximated by regression coefficients in a pooled model which excludes group membership (Neumark, 1988). Although this solution to the comparison group choice problem has been the most popular alternative to the basic Oaxaca-Blinder 
decomposition (Weichselbaumer and Winter-Ebmer, 2005), it has been criticized by both Fortin (2008) and Elder et al. (2010), since exclusion of the group membership dummy can bias coefficients on other covariates which also affects the unexplained component. Therefore, Fortin (2008) has proposed to use a pooled model including group membership as the comparison wage structure. As noted by Fortin (2008) and Fortin et al. (2011), the unexplained component in such a decomposition is equal (by construction) to the coefficient on the group membership dummy in a pooled regression.

\subsection{Oaxaca-Blinder and the Average Wage Gap}

In this subsection I provide an alternative solution to the comparison group choice problem by developing a new version of the Oaxaca-Blinder decomposition whose unexplained component recovers the average wage gap. This model also uses Equation 8 and a comparison wage structure which is constructed as a specific linear combination of the regression coefficients for both subpopulations of interest.

Proposition 1 (Oaxaca-Blinder and the Average Wage Gap). If $\beta^{*}=\mathrm{P}\left[d_{i}=0\right] \cdot \beta_{1}+$ $\mathrm{P}\left[d_{i}=1\right] \cdot \beta_{0}$, then the unexplained component of the Oaxaca-Blinder decomposition in Equation 8 recovers the average wage gap.

Proof. Combine Equation 8 with $\beta^{*}=\mathrm{P}\left[d_{i}=0\right] \cdot \beta_{1}+\mathrm{P}\left[d_{i}=1\right] \cdot \beta_{0}$ and reformulate:

$$
\begin{aligned}
\mathrm{E}\left[y_{i} \mid d_{i}=1\right]-\mathrm{E}\left[y_{i} \mid d_{i}=0\right]= & \mathrm{E}\left[X_{i} \mid d_{i}=1\right] \cdot\left(\beta_{1}-\beta^{*}\right)+\mathrm{E}\left[X_{i} \mid d_{i}=0\right] \cdot\left(\beta^{*}-\beta_{0}\right) \\
& +\left(\mathrm{E}\left[X_{i} \mid d_{i}=1\right]-\mathrm{E}\left[X_{i} \mid d_{i}=0\right]\right) \cdot \beta^{*} \\
= & \mathrm{E}\left[X_{i} \mid d_{i}=1\right] \cdot\left(\beta_{1}-\left(\mathrm{P}\left[d_{i}=0\right] \cdot \beta_{1}+\mathrm{P}\left[d_{i}=1\right] \cdot \beta_{0}\right)\right) \\
& +\mathrm{E}\left[X_{i} \mid d_{i}=0\right] \cdot\left(\left(\mathrm{P}\left[d_{i}=0\right] \cdot \beta_{1}+\mathrm{P}\left[d_{i}=1\right] \cdot \beta_{0}\right)-\beta_{0}\right) \\
& +\left(\mathrm{E}\left[X_{i} \mid d_{i}=1\right]-\mathrm{E}\left[X_{i} \mid d_{i}=0\right]\right) \cdot \beta^{*} \\
= & \mathrm{P}\left[d_{i}=1\right] \cdot \mathrm{E}\left[X_{i} \mid d_{i}=1\right] \cdot\left(\beta_{1}-\beta_{0}\right) \\
& +\mathrm{P}\left[d_{i}=0\right] \cdot \mathrm{E}\left[X_{i} \mid d_{i}=0\right] \cdot\left(\beta_{1}-\beta_{0}\right) \\
& +\left(\mathrm{E}\left[X_{i} \mid d_{i}=1\right]-\mathrm{E}\left[X_{i} \mid d_{i}=0\right]\right) \cdot \beta^{*} \\
= & \mathrm{P}\left[d_{i}=1\right] \cdot \tau_{\text {gain }}+\mathrm{P}\left[d_{i}=0\right] \cdot \tau_{\text {loss }} \\
& +\left(\mathrm{E}\left[X_{i} \mid d_{i}=1\right]-\mathrm{E}\left[X_{i} \mid d_{i}=0\right]\right) \cdot \beta^{*} \\
= & \tau_{\text {gap }}+\left(\mathrm{E}\left[X_{i} \mid d_{i}=1\right]-\mathrm{E}\left[X_{i} \mid d_{i}=0\right]\right) \cdot \beta^{*} .
\end{aligned}
$$

Although using the population proportion of advantaged workers to weight the coefficients for disadvantaged workers and using the population proportion of disadvantaged 
workers to weight the coefficients for advantaged workers may at first look counterintuitive, each of the wage structures plays a clearly defined role in such a decomposition-it serves as the counterfactual for the other group (see Assumption 1). This is exactly the reason why more weight should be put on the wage structure of the smaller group which is used to provide the counterfactual for the larger one.

Interestingly, this alternative decomposition is equivalent to a flexible linear regression model for the average treatment effect, presented in Imbens and Wooldridge (2009) and Wooldridge (2010). The average treatment effect can be recovered as the coefficient on $d_{i}$ in the regression of $y_{i}$ on $1, d_{i}, X_{i}$, and $d_{i} \cdot\left(X_{i}-\mathrm{E}\left[X_{i}\right]\right)$. Imbens and Wooldridge (2009) have noted that such a model can alternatively be written as:

$$
\begin{aligned}
\tau_{A T E}= & \mathrm{E}\left[y_{i} \mid d_{i}=1\right]-\mathrm{E}\left[y_{i} \mid d_{i}=0\right] \\
& -\left(\mathrm{P}\left[d_{i}=0\right] \cdot \beta_{1}+\mathrm{P}\left[d_{i}=1\right] \cdot \beta_{0}\right) \cdot\left(\mathrm{E}\left[X_{i} \mid d_{i}=1\right]-\mathrm{E}\left[X_{i} \mid d_{i}=0\right]\right),
\end{aligned}
$$

which is equivalent to the Oaxaca-Blinder decomposition in Proposition 1. Similarly, the unexplained component of the Oaxaca-Blinder decomposition in Equation 5 is equal to the coefficient on $d_{i}$ in the regression of $y_{i}$ on $1, d_{i}, X_{i}$, and $d_{i} \cdot\left(X_{i}-\mathrm{E}\left[X_{i} \mid d_{i}=1\right]\right)$ and the unexplained component of the Oaxaca-Blinder decomposition in Equation 6 is equal to the coefficient on $d_{i}$ in the regression of $y_{i}$ on $1, d_{i}, X_{i}$, and $d_{i} \cdot\left(X_{i}-\mathrm{E}\left[X_{i} \mid d_{i}=0\right]\right)$.

The logic and approach of Proposition 1 applies also to the well-known versions of the Oaxaca-Blinder decomposition in Reimers (1983), Cotton (1988), and Fortin (2008). It can be easily verified that $(i)$ the unexplained component of the Reimers (1983) decomposition is equal to the arithmetic average of the average wage gain for advantaged workers and the average wage loss for disadvantaged workers; (ii) the unexplained component of the Cotton (1988) decomposition is equal to a weighted average of the average wage gain for advantaged workers and the average wage loss for disadvantaged workers, with reversed weights attached to both these parameters; ${ }^{4}$ and (iii) the unexplained component of the Fortin (2008) decomposition is approximately equal to the same parameter. This last interpretation is based on the similarity between the unexplained component of the Cotton (1988) decomposition and the coefficient on the group membership dummy in a simple linear regression (Elder et al., 2010) and a related reinterpretation of the linear regression estimand in the presence of heterogeneous treatment effects (Słoczyński, 2014). In consequence, whenever we are concerned with heterogeneity in conditional wage gaps, there is good reason to choose the new version of the Oaxaca-Blinder decompo-

\footnotetext{
${ }^{4}$ In other words, the proportion of disadvantaged workers is used to weight the average wage gain for advantaged workers and the proportion of advantaged workers is used to weight the average wage loss for disadvantaged workers.
} 
sition in Proposition 1 to estimate the average wage gap. ${ }^{5}$ When instead we use the Reimers (1983), Cotton (1988), or Fortin (2008) decompositions, we risk overstating the importance of the smaller group. As an extreme example, assume that the proportion of advantaged workers goes to zero. In that case, in the limit, the unexplained components of the Cotton (1988) and Fortin (2008) decompositions approach the average wage gain for advantaged workers, i.e. the group which is nearly absent by assumption.

On the other hand, it should be noted that these interpretations of the Reimers (1983), Cotton (1988), and Fortin (2008) decompositions are based on the assumption of a simple counterfactual treatment (Assumption 1), while this assumption has not been invoked in any of these papers. More precisely, each of these papers has attempted to account for the presence of general equilibrium effects-which are ruled out by Assumption 1-and to derive a comparison wage structure which would be observed if wage discrimination ceased to exist. It is very difficult, however, to correctly guess the form of this "nondiscriminatory" or "competitive" wage structure-and Reimers (1983), Cotton (1988), and Fortin (2008) have not provided any theoretical models to rationalize their choices. In this situation we might perhaps prefer to invoke the assumption of a simple counterfactual treatment instead of relying on the general-equilibrium approach-in which case the Reimers (1983), Cotton (1988), and Fortin (2008) decompositions would be problematic.

\subsection{A Semiparametric Extension}

If we indeed decide to aim at estimating $\tau_{\text {gap }}, \tau_{\text {gain }}$, and $\tau_{\text {loss }}$, then any of the standard estimators of the average treatment effect and the average treatment effect on the treated can be used to estimate $\tau_{\text {gap }}$ and $\tau_{\text {gain }} / \tau_{\text {loss }}$, respectively, and we can safely assume that the better an estimator is for various average treatment effects, the better it is also for various averages of conditional wage gaps (for a similar discussion, see Fortin et al., 2011).

Indeed, recent applications have used reweighting (Barsky et al., 2002), matching on covariates (Black et al., 2006, 2008; Nopo, 2008), propensity score matching (Frölich, 2007), and regression trees (Mora, 2008) to study intergroup differences in various outcomes. In this subsection I demonstrate how various averages of conditional wage gaps can also be estimated using a combination of stratification (on the propensity score) and the Oaxaca-Blinder decomposition. This new estimation method is very similar to combining stratification and linear regression. Although this latter estimator is well established (see, e.g., Dehejia and Wahba, 1999; Imbens and Wooldridge, 2009), it does not allow for

\footnotetext{
${ }^{5}$ Note that there is persuasive evidence on such heterogeneity which has been accumulated in the literature on glass ceilings (see, e.g., Albrecht et al., 2003; Arulampalam et al., 2007; de la Rica et al., 2008; Chzhen and Mumford, 2011).
} 
within-strata treatment effect heterogeneity. Since the Oaxaca-Blinder decomposition can be regarded as a version of flexible OLS (in the sense that it allows for heterogeneity in effects), this shortcoming can be addressed by a combination of stratification and the Oaxaca-Blinder decomposition. On the other hand, it needs to be noted that this estimation method only allows for a very specific form of effect heterogeneity-linear in $X_{i}$.

Such an estimator of the average wage gap requires a first-step estimation of the propensity score, i.e. the conditional probability that a sample member belongs to the advantaged group given his or her covariate values. The estimated propensity score is then used to divide the whole sample into $J$ strata. For each stratum $j$, a separate estimate of the average wage gap, $\hat{\tau}_{g a p}, j$, is obtained using the decomposition in Proposition 1. Also, the estimated variance, $\hat{V}_{g a p}, j$, can be computed, and these estimates are averaged using a procedure in Imbens and Wooldridge (2009):

$$
\hat{\tau}_{g a p}=\sum_{j=1}^{J}\left(\frac{n_{j 0}+n_{j 1}}{n}\right) \cdot \hat{\tau}_{g a p, j} \quad \text { and } \quad \hat{V}_{g a p}=\sum_{j=1}^{J}\left(\frac{n_{j 0}+n_{j 1}}{n}\right)^{2} \cdot \hat{V}_{g a p, j} .
$$

Similarly, an analogous estimator of the average wage gain for advantaged workers involves estimating Equation 5 in each of the strata, while the average wage loss for disadvantaged workers can be estimated with the use of the Oaxaca-Blinder decomposition in Equation 6 . These within-strata estimates are averaged to obtain:

$$
\begin{aligned}
& \hat{\tau}_{\text {gain }}=\sum_{j=1}^{J}\left(\frac{n_{j 1}}{n_{1}}\right) \cdot \hat{\tau}_{\text {gain, } j} \quad \text { and } \quad \hat{V}_{\text {gain }}=\sum_{j=1}^{J}\left(\frac{n_{j 1}}{n_{1}}\right)^{2} \cdot \hat{V}_{\text {gain }, j}, \\
& \hat{\tau}_{\text {loss }}=\sum_{j=1}^{J}\left(\frac{n_{j 0}}{n_{0}}\right) \cdot \hat{\tau}_{\text {loss }, j} \quad \text { and } \quad \hat{V}_{\text {loss }}=\sum_{j=1}^{J}\left(\frac{n_{j 0}}{n_{0}}\right)^{2} \cdot \hat{V}_{\text {loss }, j} .
\end{aligned}
$$

These estimators require fewer functional form assumptions compared with the fully parametric approach, and such a property might be important to ensure robustness in the presence of nonlinearities in the existing wage structures (see, e.g., Barsky et al., 2002). They can also provide a useful alternative outside the decomposition context, and can be used to estimate the average treatment effect or the average treatment effect on the treated. These estimators are tested in an empirical application in the next section together with parametric Oaxaca-Blinder decompositions and normalized reweighting, which has performed very well in a recent Monte Carlo study by Busso et al. (2014). 


\section{An Empirical Application}

In this section various versions of the Oaxaca-Blinder decomposition are compared in an application to the UK gender wage gap. The source of data is the Quarterly Labour Force Survey (LFS), 2002Q1-2010Q4 (Office for National Statistics, Various years). In this application I append all the quarterly datasets and restrict the resulting sample in such a way that yearly representative results, for each year from 2002 to 2010, can be produced.

I further restrict the 2002-2010 LFS dataset to those individuals who are at least 18 years old, have reported nonzero average gross hourly pay, and do not have missing information on any of the control variables specified below. The outcome variable is the log hourly wage. The set of control variables includes polynomials in age, tenure, and potential experience as well as dummies for marital status ( 5 categories), ethnic origin (11 categories), country of residence (4 categories), occupation (9 categories), and public/private sector. For current students, potential experience is coded as 0 . For individuals with no education, potential experience is coded as the number of years since the age of fifteen.

In all instances, the estimation is done using weighted least squares, with weights recommended for income data. In particular, I estimate $\beta_{1}$ and $\beta_{0}$ in Equation 4 by WLS, and apply the results to construct estimates of unexplained components of various versions of the Oaxaca-Blinder decomposition (Equations 7 and 8). Whenever I need to estimate $\mathrm{E}\left[X_{i} \mid d_{i}=1\right], \mathrm{E}\left[X_{i} \mid d_{i}=0\right], \mathrm{P}\left[d_{i}=1\right]$, or $\mathrm{P}\left[d_{i}=0\right]$, I use (weighted) sample means. Because $\beta^{*}$ in the Neumark (1988) and Fortin (2008) decompositions cannot be easily constructed from $\beta_{1}$ and $\beta_{0}$, I estimate it directly, again using weighted least squares. ${ }^{6}$

Table 1 presents descriptive statistics for outcome and selected control variables in all the yearly samples and Table 2 presents estimates of unexplained components of various versions of the Oaxaca-Blinder decomposition (including $\hat{\tau}_{g a p}, \hat{\tau}_{g a i n}$, and $\hat{\tau}_{\text {loss }}$ ) as well as yearly measures of the raw wage gap. All these measures have generally been falling between 2002 and 2010, and have reached their minimum values in 2010. For example, the estimate of the raw wage gap has fallen from 23.06 to $16.86 \log$ points, while $\hat{\tau}_{\text {gain }}$ and $\hat{\tau}_{\text {loss }}$ have fallen from 19.97 to 15.69 and from 15.59 to 12.28 log points, respectively.

There are several other empirical regularities which are worth mentioning. The average wage gain for men is larger than the average wage loss for women in a very robust way. This difference was as large as 3-5 log points in all years and always statistically

\footnotetext{
${ }^{6}$ All the applications of the Oaxaca-Blinder decomposition presented in this paper use the oaxaca command in Stata (Jann, 2008). The new version of the Oaxaca-Blinder decomposition in Proposition 1 is also easily implementable using this command. If local macros prf and xvars contain the proportion of women in the estimation sample and the list of control variables, respectively, then this decomposition can be applied as oaxaca lnwage 'xvars', by (female) weight('prf'). Note that the oaxaca command calculates standard errors which account for the stochastic nature of sample means of control variables.
} 
Figure 1: A Comparison of the Average Wage Gain for Men and the Average Wage Loss for Women in the UK Labor Market

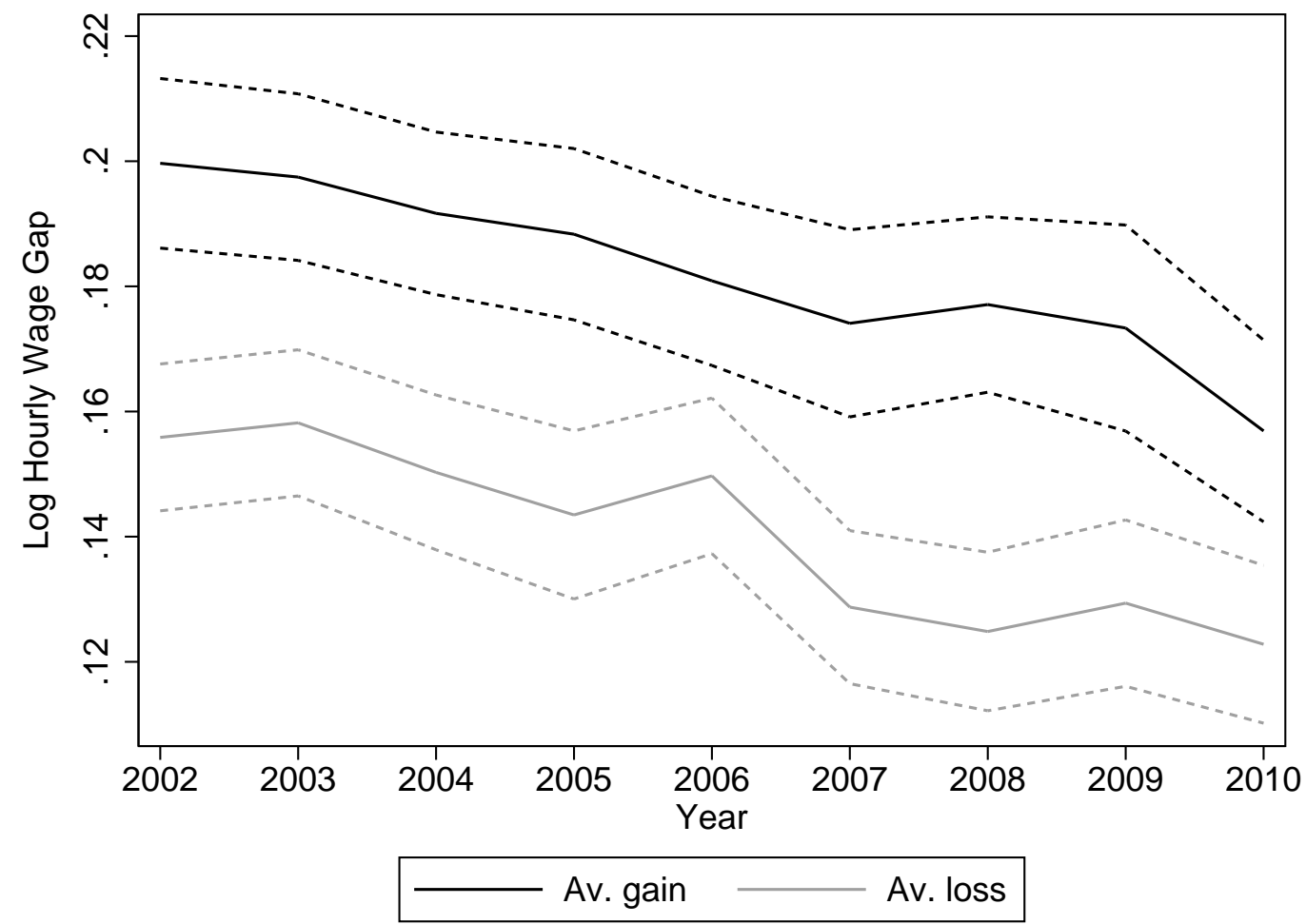

significant at the $1 \%$ level. ${ }^{7}$ Such a phenomenon has already been documented in the wage gap literature, but without a clear interpretation (see, e.g., Fortin et al., 2011). More precisely, this empirical regularity was typically understood as an "indeterminacy" of Oaxaca-Blinder decompositions. Such a claim is untenable, however, within the framework of this paper, in which each of these parameters $-\tau_{\text {gain }}$ and $\tau_{\text {loss }}$-has a different interpretation. If $\tau_{\text {gain }}$ is significantly larger than $\tau_{\text {loss }}$, then men gain typically more in comparison with similar women than women lose in comparison with similar men. Because men are located, on average, higher in the wage distribution than women, such a phenomenon means that conditional wage gaps tend to increase with wages. Indeed, the coefficient estimates for a series of quantile regressions suggest that in most years wage gaps at the top of the UK wage distribution (90th centile) were at least 3 log points larger than at the bottom of this distribution (10th centile). ${ }^{8}$ Both time series of estimates $\left(\hat{\tau}_{\text {gain }}\right.$

\footnotetext{
${ }^{7}$ All the tests of statistical significance referred to in this section are based on bootstrap standard errors of the estimated differences between the unexplained components of various versions of the Oaxaca-Blinder decomposition (with 1,000 resamples).

${ }^{8}$ One can also suspect the existence of the so-called glass ceiling effect. However, the results of the quantile regressions provide mixed evidence on the existence of a glass ceiling in the UK labor market. Although wage gaps generally increase throughout the wage distribution, their acceleration in this distri-
} 
Figure 2: A Comparison of Unexplained Components of Various Versions of the OaxacaBlinder Decomposition-in an Application to the UK Labor Market

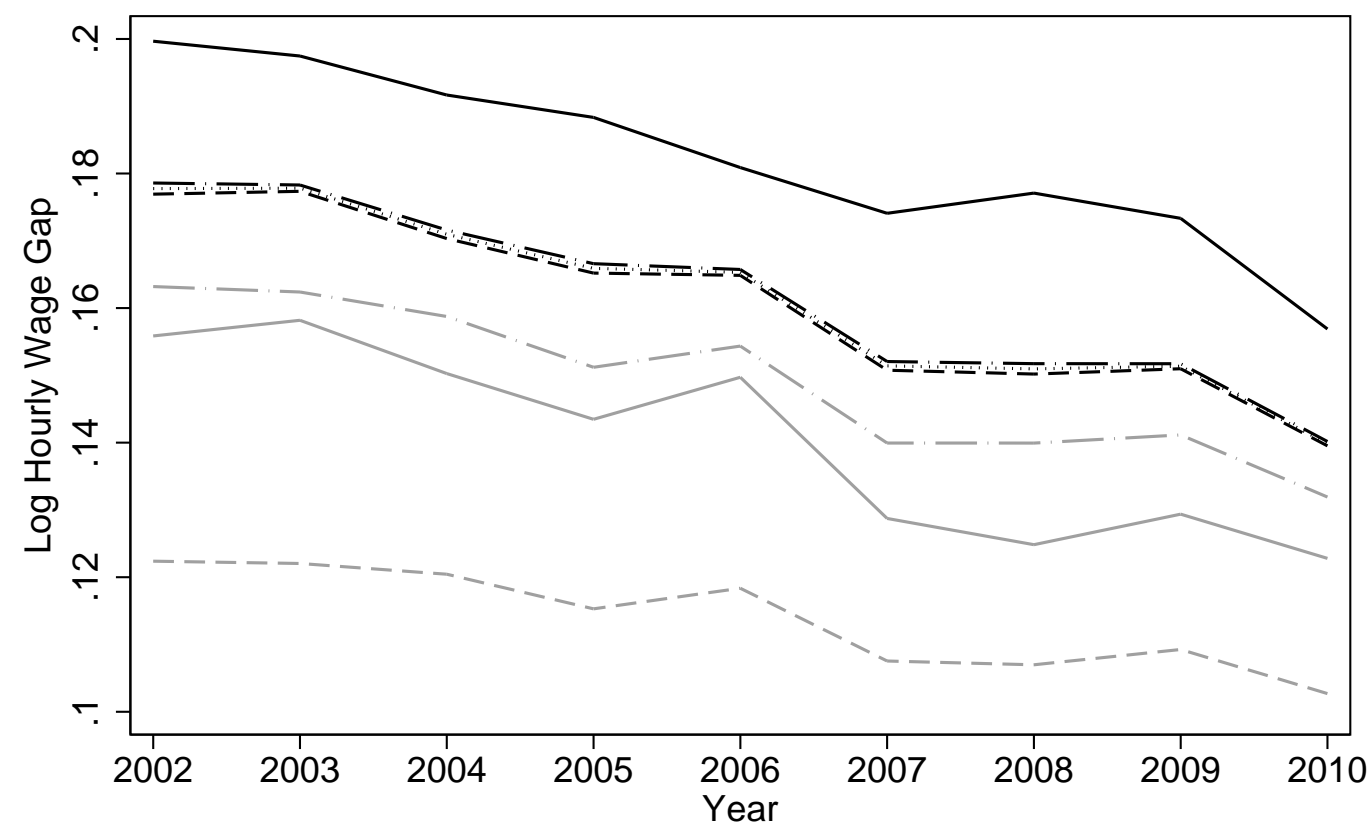

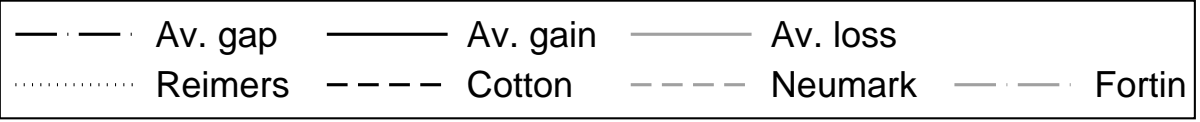

and $\left.\hat{\tau}_{\text {loss }}\right)$ are also plotted in Figure 1, together with 95\% confidence intervals.

At the same time, the Reimers (1983) and Cotton (1988) estimates of the unexplained component as well as the Oaxaca-Blinder estimates of $\tau_{\text {gap }}$ lie always (by construction) in between the corresponding estimates of $\tau_{\text {gain }}$ and $\tau_{\text {loss }}$. The Reimers (1983), Cotton (1988), and $\tau_{\text {gap }}$ estimates are, however, not only bounded by $\hat{\tau}_{\text {gain }}$ and $\hat{\tau}_{\text {loss }}$, but also exactly equal (again by construction) to their weighted average, with weights equal to sample proportions of men and women $\left(\tau_{\text {gap }}\right)$, reversed sample proportions of both groups (Cotton, 1988), and 0.5 and 0.5 (Reimers, 1983). Moreover, the Neumark (1988) estimates of the unexplained component are always significantly lower (again, at the $1 \%$ level) than any other estimates (for a theoretical explanation, see Elder et al., 2010).

All of these time series of estimates, together with $\hat{\tau}_{\text {gain }}, \hat{\tau}_{\text {loss }}$, and Fortin (2008), are also plotted in Figure 2. As evident in Figure 2, the differences between $\hat{\tau}_{g a p}$ and the Reimers (1983) and Cotton (1988) estimates are quantitatively quite small. Note, however, that this is an artifact of nearly equal sample proportions of men and women in bution's upper tail can rarely be regarded as "sharp". See Arulampalam et al. (2007) for related evidence on glass ceilings across EU countries as well as Chzhen and Mumford (2011) for a more recent study of the United Kingdom. 
the LFS data. If these proportions were significantly different (e.g., when analyzing ethnic/racial wage gaps, or union wage premiums, or gender wage gaps within a predominantly male/female occupation), the estimates would tend to diverge.

Also, note that these differences, however small, are always statistically significant. Further evidence on the differences between various Oaxaca-Blinder decompositions is provided in Table 3 by presenting bootstrap standard errors (based on 1,000 resamples) of the estimated differences between $\hat{\tau}_{g a p}$ and other Oaxaca-Blinder estimators of the unexplained component, and testing the statistical significance of these differences. All these differences are statistically significant at the $5 \%$ level in all years (and, in most cases, also at the $1 \%$ level). We get the expected result that $\hat{\tau}_{g a p}$ is always significantly smaller than $\hat{\tau}_{\text {gain }}$ and larger than $\hat{\tau}_{\text {loss }}$. Also, consistent with the evidence in Elder et al. (2010), $\hat{\tau}_{\text {gap }}$ is always significantly larger than the unexplained component of the Neumark (1988) decomposition, and this difference is quantitatively quite large (4-6 log points). Importantly, however, Table 3 reestablishes the empirical relevance of this paper's claim that the Reimers (1983), Cotton (1988), and Fortin (2008) decompositions might estimate weighted averages of conditional wage gaps which are difficult to interpret. In all years these decompositions overstate the importance of $\hat{\tau}_{\text {loss }}$ (the effect on the smaller subpopulation) in estimating average wage gaps, and consequently $\hat{\tau}_{\text {gap }}$ is always significantly larger than the unexplained components of these decompositions (because $\left.\hat{\tau}_{\text {gain }}>\hat{\tau}_{\text {loss }}\right) .{ }^{9}$ In other words, using the Reimers (1983), Cotton (1988), or Fortin (2008) decompositions would negatively bias the estimate of the average wage gap in an application to the UK labor market, although these biases can be quite small in the present application.

As a robustness check, Table 4 presents a comparison of various estimators of $\tau_{g a p}$, $\tau_{\text {gain }}$, and $\tau_{\text {loss }}$, both parametric (Oaxaca-Blinder) and semiparametric (stratification and Oaxaca-Blinder, normalized reweighting). Importantly, all the qualitative results on the relationship between the average wage gain for men and the average wage loss for women

\footnotetext{
${ }^{9} \mathrm{At} \mathrm{first,} \mathrm{this} \mathrm{might} \mathrm{be} \mathrm{seen} \mathrm{as} \mathrm{surprising,} \mathrm{given} \mathrm{the} \mathrm{small} \mathrm{differences} \mathrm{between} \hat{\tau}_{\text {gap }}$ and selected other estimates. Take the difference between $\hat{\tau}_{g a p}$ (17.86 log points) and the Reimers (1983) estimate (17.78 log points) in 2002 as an example. Both these parameters are estimated with an error of $0.56 \log$ points, so it is natural to expect that the difference of $0.08 \mathrm{log}$ points between them is not statistically significant. As shown in Table 3, however, this is not the case, since this difference is actually estimated with a very small error of 0.02. Why is the initial intuition wrong? First, note that these estimates are (by construction) positively correlated over repeated samples. When $\hat{\tau}_{g a p}$ is relatively large, the Reimers (1983) estimate is also likely to be large, but probably smaller than $\hat{\tau}_{\text {gap }}$ (since $\hat{\tau}_{\text {gain }}>\hat{\tau}_{\text {loss }}$ ). Second, note that the null hypothesis of $\mathrm{P}\left[d_{i}=1\right] \cdot \tau_{\text {gain }}+\mathrm{P}\left[d_{i}=0\right] \cdot \tau_{\text {loss }}=\frac{1}{2} \cdot \tau_{\text {gain }}+\frac{1}{2} \cdot \tau_{\text {loss }}$ can be equivalently written as $\left(\mathrm{P}\left[d_{i}=1\right]-\frac{1}{2}\right) \cdot\left(\tau_{\text {gain }}-\tau_{\text {loss }}\right)=0$. That the second factor $\left(\tau_{\text {gain }}-\tau_{\text {loss }}\right)$ is significantly larger than zero is evident from Figure 1. Using a one-proportion z-test and data in Table 1 , the equality of $\mathrm{P}\left[d_{i}=1\right]$ and $\frac{1}{2}$ can also be rejected (in favor of $\mathrm{P}\left[d_{i}=1\right]>\frac{1}{2}$ ). Of course, a similar logic applies also to other tests of statistical significance in Table 3.
} 
are confirmed. Also, the trends in the estimated wage gaps are very similar. This pattern is consistent with the recent evidence in Nopo (2008) who has concluded that the linearity assumption is not particularly problematic when decomposing gender wage gaps.

\section{Summary}

In this paper I have argued for a decomposition framework in which current wages of advantaged workers are compared with current wages of similar disadvantaged workers (and vice versa), and not with an hypothesized "nondiscriminatory" wage structure. To provide a tool for such comparisons, I have derived an alternative solution to the comparison group choice problem which is fundamental in Oaxaca-Blinder, while this new decomposition can be used to estimate the average wage gap and the average treatment effect. I have also pointed out that several other versions of the Oaxaca-Blinder decomposition (Reimers, 1983; Cotton, 1988; Fortin, 2008) can produce misleading results in empirical applications, since each of them is likely to overstate the importance of the smaller of the subpopulations (e.g., men and women, treated and controls, union and nonunion workers) when estimating various averages of conditional wage gaps or treatment effects.

This approach has also been illustrated empirically in an application to UK gender wage gaps. Using data from the Quarterly Labour Force Survey (LFS) I have estimated the average wage gap, the average wage gain for men, and the average wage loss for women for the UK working population, for each year from 2002 to 2010. The major empirical finding of this study is that men gain typically more in comparison with similar women than women lose in comparison with similar men ( $\tau_{\text {gain }}$ is larger than $\left.\tau_{\text {loss }}\right)$. This phenomenon is explained by the fact that conditional wage gaps tend to increase with wages and this is indeed the case in the UK labor market.

Future work might involve establishing formal conditions under which causal effects of gender and other immutable characteristics can be identified and estimated (for recent discussions, see Kunze, 2008, Greiner and Rubin, 2011, and Huber, 2014) and, as already suggested by Fortin et al. (2011), improving the economic structure behind decomposition methods. It is also essential to understand the links between the decomposition methods and the treatment effects framework. Following an important review in Fortin et al. (2011), this paper has attempted to take this ongoing discussion one step further by providing a new (Oaxaca-Blinder) model for the average wage gap which-under a particular causal framework—corresponds to the average treatment effect. 


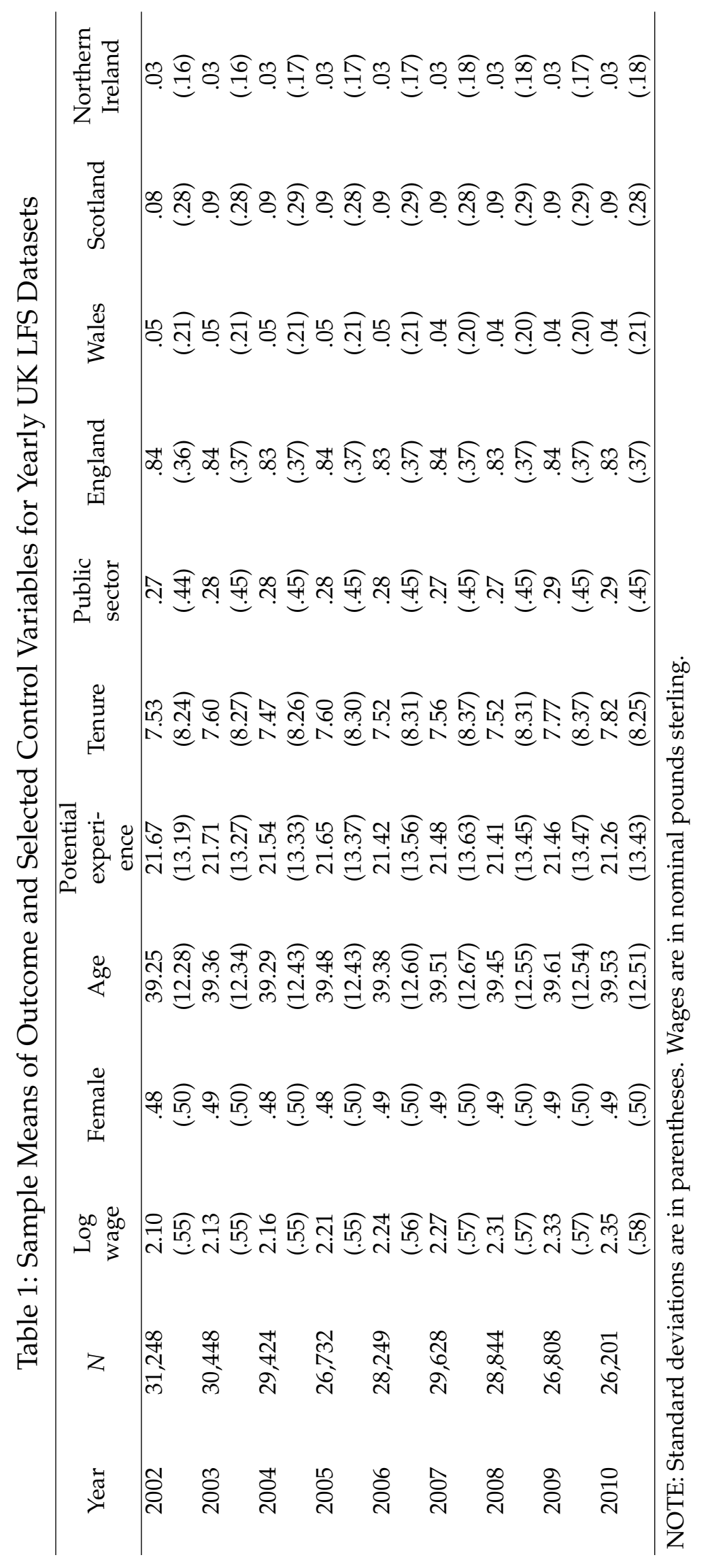




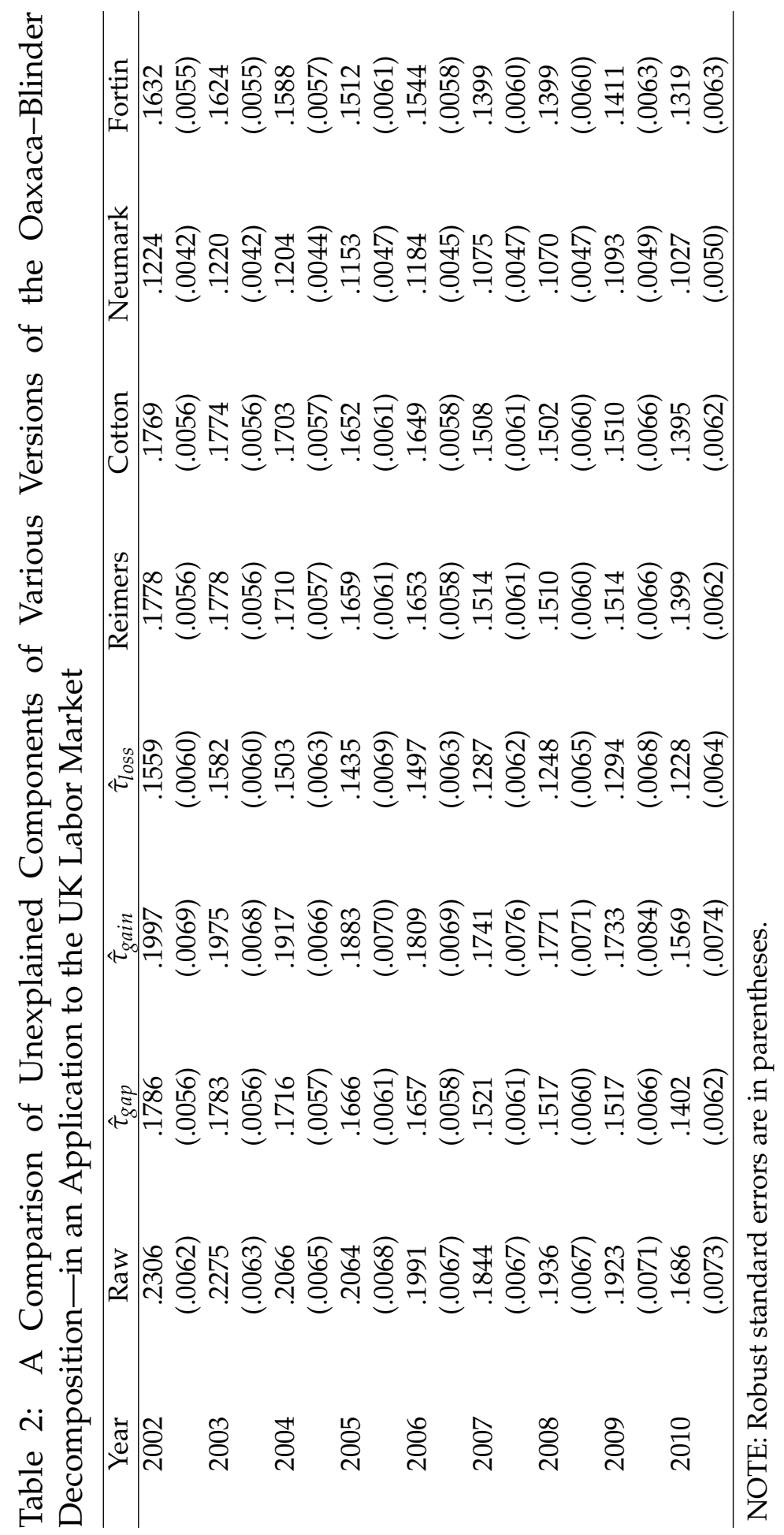




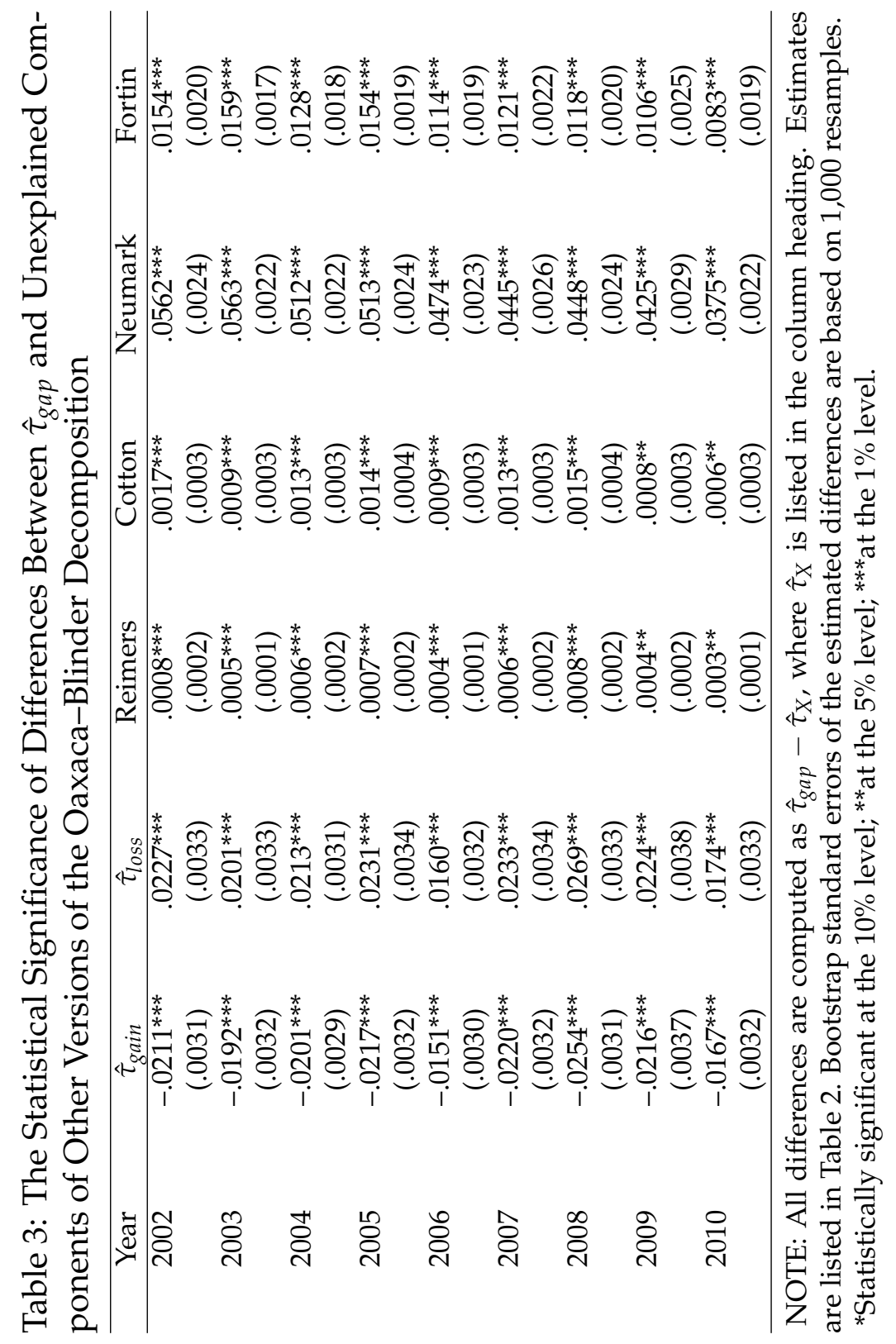




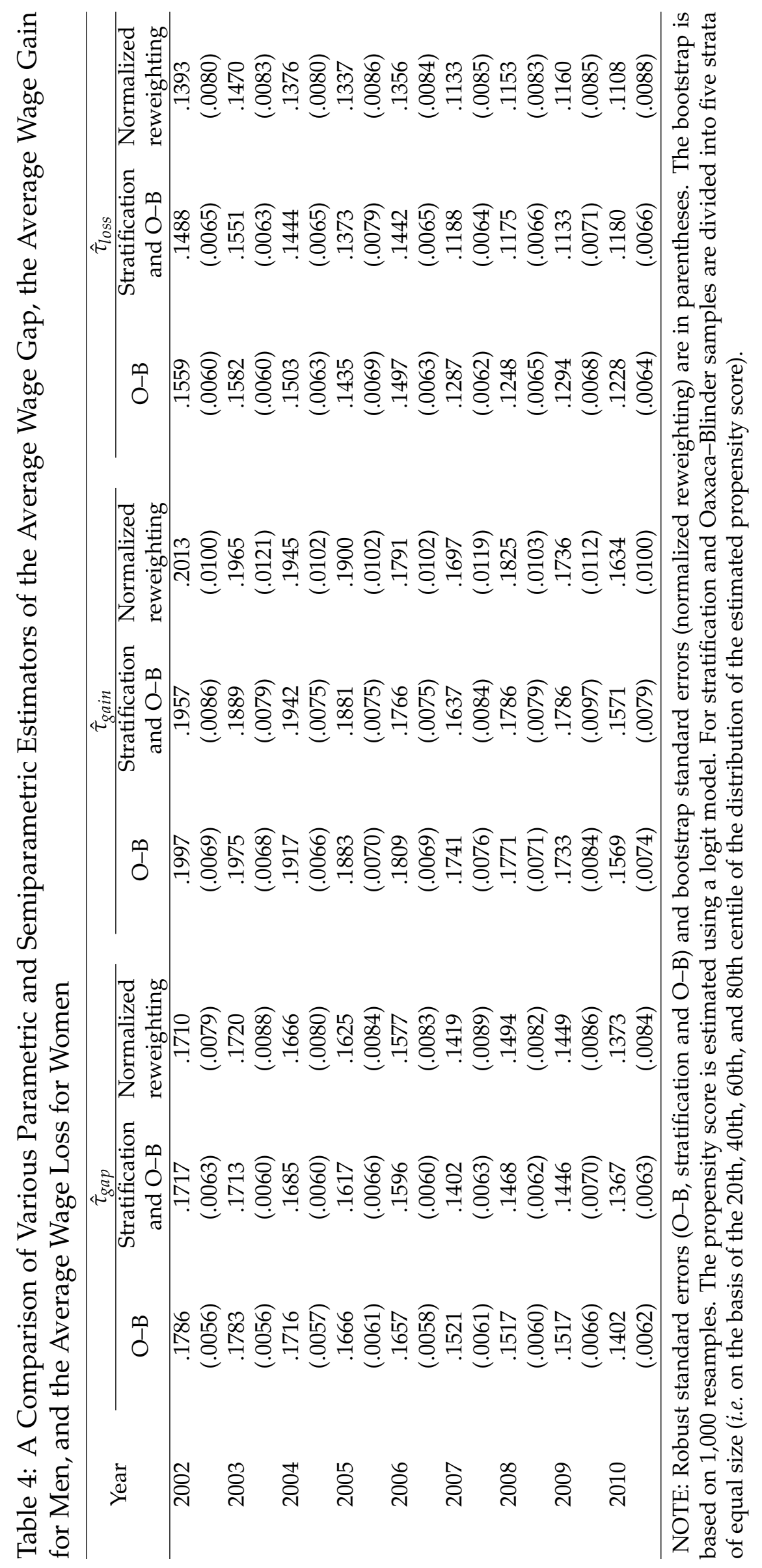




\section{References}

AlBrecht, J., BJÖRKLUnd, A. \& VROMAN, S. (2003). Is there a glass ceiling in Sweden? Journal of Labor Economics 21, 145-177.

Arulampalam, W., Booth, A. L. \& Bryan, M. L. (2007). Is there a glass ceiling over Europe? Exploring the gender pay gap across the wage distribution. Industrial and Labor Relations Review 60, 163-186.

Barsky, R., Bound, J., Charles, K. K. \& Lupton, J. P. (2002). Accounting for the black-white wealth gap: A nonparametric approach. Journal of the American Statistical Association 97, 663-673.

Black, D., Haviland, A., SANDers, S. \& TAYlor, L. (2006). Why do minority men earn less? A study of wage differentials among the highly educated. Review of Economics and Statistics 88, 300-313.

Black, D. A., Haviland, A. M., SAnders, S. G. \& TAYlor, L. J. (2008). Gender wage disparities among the highly educated. Journal of Human Resources 43, 630-659.

BLACKBURN, M. L. (2004). The role of test scores in explaining race and gender differences in wages. Economics of Education Review 23, 555-576.

Blinder, A. S. (1973). Wage discrimination: Reduced form and structural estimates. Journal of Human Resources 8, 436-455.

Brown, C. \& CORCORAN, M. (1997). Sex-based differences in school content and the male-female wage gap. Journal of Labor Economics 15, 431-465.

Busso, M., DiNARdo, J. \& MCCRARY, J. (2014). New evidence on the finite sample properties of propensity score reweighting and matching estimators. Review of Economics and Statistics 96, 885-897.

Chernozhukov, V., Fernández-VAl, I. \& Melly, B. (2013). Inference on counterfactual distributions. Econometrica 81, 2205-2268.

ChzHEN, Y. \& Mumford, K. (2011). Gender gaps across the earnings distribution for full-time employees in Britain: Allowing for sample selection. Labour Economics 18, 837-844.

Cotton, J. (1988). On the decomposition of wage differentials. Review of Economics and Statistics 70, 236-243. 
DE LA RicA, S., Dolado, J. J. \& Llorens, V. (2008). Ceilings or floors? Gender wage gaps by education in Spain. Journal of Population Economics 21, 751-776.

DeHEJiA, R. H. \& WAHBA, S. (1999). Causal effects in nonexperimental studies: Reevaluating the evaluation of training programs. Journal of the American Statistical Association 94, 1053-1062.

DiNardo, J., Fortin, N. M. \& Lemieux, T. (1996). Labor market institutions and the distribution of wages, 1973-1992: A semiparametric approach. Econometrica 64, 10011044.

DunCan, G. M. \& Leigh, D. E. (1985). The endogeneity of union status: An empirical test. Journal of Labor Economics 3, 385-402.

Elder, T. E., GodDEeris, J. H. \& HAider, S. J. (2010). Unexplained gaps and OaxacaBlinder decompositions. Labour Economics 17, 284-290.

Firpo, S., FORTIN, N. \& LEMIEUX, T. (2007). Decomposing wage distributions using recentered influence function regressions. Unpublished.

Fortin, N., LeMieUX, T. \& Firpo, S. (2011). Decomposition methods in economics. In: Handbook of Labor Economics (ASHENFELTER, O. \& CARD, D., eds.), vol. 4A. Elsevier.

FORTIN, N. M. (2005). Gender role attitudes and the labour-market outcomes of women across OECD countries. Oxford Review of Economic Policy 21, 416-438.

FORTIN, N. M. (2008). The gender wage gap among young adults in the United States: The importance of money versus people. Journal of Human Resources 43, 884-918.

FRÖLICH, M. (2007). Propensity score matching without conditional independence assumption - with an application to the gender wage gap in the United Kingdom. Econometrics Journal 10, 359-407.

GReineR, D. J. \& Rubin, D. B. (2011). Causal effects of perceived immutable characteristics. Review of Economics and Statistics 93, 775-785.

Holland, P. W. (1986). Statistics and causal inference. Journal of the American Statistical Association 81, 945-960.

Huber, M. (2014). Causal pitfalls in the decomposition of wage gaps. Journal of Business $\mathcal{E}$ Economic Statistics (forthcoming). 
ICHINO, A. \& MoretTI, E. (2009). Biological gender differences, absenteeism, and the earnings gap. American Economic Journal: Applied Economics 1, 183-218.

Imbens, G. W. \& WoOlDRIDGE, J. M. (2009). Recent developments in the econometrics of program evaluation. Journal of Economic Literature 47, 5-86.

JANN, B. (2008). The Blinder-Oaxaca decomposition for linear regression models. Stata Journal 8, 453-479.

Juhn, C., Murphy, K. M. \& Pierce, B. (1993). Wage inequality and the rise in returns to skill. Journal of Political Economy 101, 410-442.

Kline, P. (2011). Oaxaca-Blinder as a reweighting estimator. American Economic Review: Papers \& Proceedings 101, 532-537.

KunZe, A. (2008). Gender wage gap studies: Consistency and decomposition. Empirical Economics 35, 63-76.

LeibBrandT, A. \& LIST, J. A. (2014). Do women avoid salary negotiations? Evidence from a large-scale natural field experiment. Management Science (forthcoming).

LOURY, L. D. (1997). The gender earnings gap among college-educated workers. Industrial and Labor Relations Review 50, 580-593.

MACHADO, J. A. F. \& MATA, J. (2005). Counterfactual decomposition of changes in wage distributions using quantile regression. Journal of Applied Econometrics 20, 445-465.

MACHIN, S. \& PUHANI, P. A. (2003). Subject of degree and the gender wage differential: Evidence from the UK and Germany. Economics Letters 79, 393-400.

MANNING, A. \& SWAFFIELD, J. (2008). The gender gap in early-career wage growth. Economic Journal 118, 983-1024.

Melly, B. (2005). Decomposition of differences in distribution using quantile regression. Labour Economics 12, 577-590.

Melly, B. (2006). Applied quantile regression. PhD dissertation.

MorA, R. (2008). A nonparametric decomposition of the Mexican American average wage gap. Journal of Applied Econometrics 23, 463-485.

Mueller, G. \& PLUG, E. (2006). Estimating the effect of personality on male and female earnings. Industrial and Labor Relations Review 60, 3-22. 
Neumark, D. (1988). Employers' discriminatory behavior and the estimation of wage discrimination. Journal of Human Resources 23, 279-295.

OAXACA, R. (1973). Male-female wage differentials in urban labor markets. International Economic Review 14, 693-709.

OAXACA, R. L. \& RANSOM, M. R. (1988). Searching for the effect of unionism on the wages of union and nonunion workers. Journal of Labor Research 9, 139-148.

OAXACA, R. L. \& RANSOM, M. R. (1994). On discrimination and the decomposition of wage differentials. Journal of Econometrics 61, 5-21.

OfFice for NAtional StATistics (Various years). Quarterly Labour Force Survey. UK Data Archive.

Ñopo, H. (2008). Matching as a tool to decompose wage gaps. Review of Economics and Statistics 90, 290-299.

ReImers, C. W. (1983). Labor market discrimination against Hispanic and black men. Review of Economics and Statistics 65, 570-579.

SŁOCZYŃSKI, T. (2014). New evidence on linear regression and treatment effect heterogeneity. Unpublished.

Weichselbaumer, D. \& WinteR-EbmeR, R. (2005). A meta-analysis of the international gender wage gap. Journal of Economic Surveys 19, 479-511.

Wooldridge, J. M. (2010). Econometric Analysis of Cross Section and Panel Data. MIT Press, 2nd ed. 